\title{
Diagnostische Notizen
}

Bachstez: Funktioneller Blepharospasmus und Blick nach aufwärts.

Wien. klin. Woch. 1917. S. 1579.

B. verbindet die maximale Blickwendung nach oben als Hilfsmittel, einen Blepharospasmus als funktionell zu diagnostizieren.

Der Versuch wird derart gemacht, daß man dem Patienten beide Lidspalten mit Zeigefinger und Daumen offen halt und ihn oft nach-einander rasch wechselnd nach den verschiedensten

Richtungen blicken läßt. Am leichtesten wird dies zu erreichen sein, indem man die Patienten einen Gegenstand oder die Fingerspitze einer Hilfsperson, die nach alien Richtungen geführt wird, fixieren läßt. Hat man auf diese Art eine maximale Blickwendung nach aufwärts erreicht, so läßt man unauffällig, ohne die Hand selbst zu bewegen, die Lider aus und wird beobachten^ können, daß der Patient einen Moment die Augen offen halt, wenn funktioneller Blepharospasmus vorliegt. Urn die Diagnose ,funktionelГ" darauf zu stützen, genügt es natürlich nicht, wenn nur eine teilweise schmale Öffnung vom Patienten beibehalten wird. Dies könnte ja für einige Sekunden auch bei einem reflektorischen Lidkrampf mit Heran-ziehung aller Hilfsmuskeln der Fall sein. Nur ein vollständiges Offen-bleiben der Lidspalte wie bei einem normalen Auge kann zur Diagnose verwertet werden.

B. benutzt diese Erscheinung auch zur Therapie dieser Fälle. Man veranlaßt den Patienten durch Folgen des vorgehaltenen Fingers maximal nach oben zu sehen, während man die Lider offen halt. Tut er das, so läßt man die Lider vorsichtig los; die Augen bleiben einen Moment offen. Diese Tatsache wird dem Patienten vorgehalten; er erhält eine 24 stündige Frist, fleißig das Öffnen der Augen zu üben, da es ja nun erwiesen sei, daß dies im Bereiche seines Willens gelegen ist. Im Notfalle hilft ein doppelseitiger Okklusivverband.

Cords-Bonn.

Berichtigung

zu dem Aufsatz: Über den Einfl·uß des zweiäugigen Sehens auf den Nystagmus. Von Dr. Joh. Ohm im Bd. 38, Heft 5-6 dieser Zeitschrift.

S. 270, Zeile 21: In ,,ersterem" statt letzterem.

S. 272, Fig. 2 muß als Fig. 1 bezeichnet werden und die Unterschrift haben: + Schirm vor rechtem Auge (Linksruoke).

Fig. 1 muß als Fig. 2 bezeißhnet werden und die Unterschrift haben + Schirm vor linkem Auge (Reehtsmeke).

Fig. 6: ,,R. n. L.” statt richtig. 